\title{
Assessment of patellar alignment in different postures
}

\section{Hugo Machado Sanchez ${ }^{1}$, Eliane Gouveia de Morais Sanchez ${ }^{2}$, Mario Antonio Baraúna ${ }^{3}$, Roberto Sérgio de Tavares Canto ${ }^{4}$}

\author{
${ }^{1}$ Master Physical Therapy, Teacher of Physical Therapy in UniRV (University of Green River), Rio Verde-GO, Brazil \\ ${ }^{2}$ Master in Education (UFU), Rio Verde-GO, Brazil \\ ${ }^{3} \mathrm{PhD}$. in Motricity Human for University of Lisboa (POR), Uberlândia-MG, Brazil \\ ${ }^{4}$ Post-doctoral in Traumatology for University of Liverpool (ING), Uberlândia-MG, Brazil
}

\section{Email address:}

hmsfisio@yahoo.com.br (H. M. Sanchez)

\section{To cite this article:}

Hugo Machado Sanchez, Eliane Gouveia de Morais Sanchez, Mario Antonio Baraúna, Roberto Sérgio de Tavares Canto. Assessment of Patellar Alignment in Different Postures. American Journal of Sports Science. Vol. 2, No. 2, 2014, pp. 30-34.

doi: 10.11648/j.ajss.20140202.14

\begin{abstract}
Introduction: The evaluation of $\mathrm{Q}$ angle is a common clinical practice however standardization regarding the best way does not exist. Objective: Compare the value of the Q angle in different static positions and rotations of lower limbs. Methods: Evaluated 56 volunteers, 30 women and 26 men, in the supine andunder static weight-bearing positions with parallel feet and with outward foot rotation. For calculate Q angle used Computerized Biophotogrammetry. Results: Have significant difference between the static weight-bearing position with parallel feet and static weight-bearing with outward foot rotation in the left side for both the sexes $(\mathrm{p}=0.00)$ and between the supine position with outward foot rotation and static weight-bearing with parallel feet of the left side $(p=0.03)$, in the feminine sex. Conclusion: it is concluded that there are no differences between different positions and postures to review the Q angle, however we stress the importance of checking the relaxation of the muscles of the lower limbs.
\end{abstract}

Keywords: Q angle, Alignment, Evaluation, Computerized Biophotogrammetry

\section{Introduction}

The quadriceps angle, or $\mathrm{Q}$ angle is the angle formed by the meeting of two lines, one part of the anterior superior iliac spine (ASIS) and goes to the center of the patella, and another that goes from the tibial tuberosity to the center of patella ${ }^{1-7}$. It is a clinical measure used to measure knee alignment with respect to the hip, femur and tibia, as well as evaluating the alignment of the patella ${ }^{5,9}$. However, there is no universal acceptance of normal or abnormal Q angle due to the lack of a reliability coefficient and the different methods of measurement for this angle ${ }^{7}$.

According to Livingston; Mandingo ${ }^{8}$, the symmetry of the $\mathrm{Q}$ angle between members is also because of disagreements among different authors in their study evaluated 75 volunteers divided into three groups (no anterior knee pain, pain unilateral and bilateral pain) and verified by analysis protractor with volunteers standing upright, the values of the angles were asymmetric for the three groups, but that this asymmetry varied between groups .
Besides the $\mathrm{Q}$ angle assist in indicating the force vector acting on the patela ${ }^{1,2,5,6,9}$, is also used as a criterion to identify candidates for surgery or predictor of risk of injury $5,6,9$. So that changes in the value of $Q$ angle are associated with chondromalacia patella, lateral dislocation of the patella , patellar cartilage and erosion of the lateral condyle, femoral internal rotation, foot pronation and internal tibial torsion $^{3,4,7}$. According Devan et al. ${ }^{10}$, changes in Q angle in valgus knees alter the biomechanics and impairs muscle levers and therefore its functions.

The $Q$ angle shows an inverse relationship with quadriceps strength, thus the smaller the angle the greater the force produced by the quadriceps, which assumes that individuals with above normal $Q$ angle have lower quadriceps strength and are more subject to diseases of the joint patellofemoral ${ }^{6}$.

The value of $\mathrm{Q}$ angle varies according to the sex of the patient, the state of contraction of the quadriceps and the position adopted by the patient, standing or supine ${ }^{3}$. The rotation of the lower limbs have direct influence on the alignment of the knees, changing them according to their placement ${ }^{4,5,8,11-13}$. The lack of a consensus on the normal Q 
angle is partly due to the absence of a standard positioning for measuring the angle ${ }^{5}$.

The computerized biophotogrammetry uses the principle to photogrammetric images. It shows how non invasive, offering low-cost acquisition system and image interpretation, as well as the high accuracy and reproducibility. The image interpretation is the constant observation of the image to completion and issuance of a relevant report. References are marked in subjects evaluated by computerized biophotogrammetry. This demarcation is fundamental to the study and analysis of $\operatorname{dados}^{11}$. Other studies have already used this resource to evaluate the $\mathrm{Q}$ angle confirming its practicality and effectiveness ${ }^{7,18}$.

Thus, the aim of this study was to compare the values of the $\mathrm{Q}$ angle in relation to supine and standing.

\section{Material and Methods}

To carry out this study, we randomly selected 56 volunteers - 26 men and 30 women, all undergraduates.

Included in this study university without pathological complaints in the lower limbs, and sedentary. Being excluded individuals with presence of musculoskeletal injuries in the lower limbs, lower limbs discrepancy greater than $1.5 \mathrm{~cm}$, which have suffered fracture, dislocation, or previous surgery of the lower limbs, obese, with diseases of the bone, muscle or connective with neurological disorders or with sequelae of poliomyelitis and volunteers who were in the gestational period.

This study was performed after approval (opinion $\mathrm{s} / \mathrm{n}$ ) of the Ethics in Human Research following the existents regulations. Participants were informed about the objectives of the study and had free will to choose to participate or not the same.

The volunteers who agreed to participate in the study signed a Letter of Informed Consent and underwent an assessment where held by the same person. Then it was done filling the evaluation form that contained the personal data of volunteers, the length of the lower limbs and issues related to the exclusion criteria. Has completed filling up the identification of anatomical landmarks and placement of markers, positioning the participant to capture the image, and the photographic record.

Then, for continuation of proceedings volunteers remained barefoot and appropriate clothing (shorts or underwear), so as to be easily located and viewed the anatomical points. The identification and demarcation of anatomical points - anterior superior iliac spine and the tibial tuberosity - was through palpatory anatomy. The center point of the patella was located by using the caliper for a reliable determination of this point.

After identification of anatomical landmarks, they were marked with labels delimiting circular self -adhesive.

Demarcated the anatomical landmarks for the Q angle the process of data collection proceeded as follows.

For the standardization of the image, with the volunteer standing upright, two sites were previously demarcated on the ground, was the first demarcated following the suggestion of Livingston; Spaulding ${ }^{5}$, in which the feet are placed together touching medially (standing position with feet parallel - OPP), lined with an adhesive on the floor. The volunteers were instructed to keep the quadriceps muscle of both limbs relaxed, eyes to the horizon and arms along the body (Figure 1A). Then immediately proceeded to obtain the second image, in which the volunteer remained standing upright and maintained a separation of $7.5 \mathrm{~cm}$ heel and forefoot external rotation of 10 degrees from the midline 13 (standing position with feet abducted OPA), quadriceps relaxed, eyes to the horizon and arms along the body (Figure 1B). To obtain the images with the volunteers in the upright position, the camera was positioned on a tripod level and plumb to a height of 0.90 $\mathrm{m}$ above the ground and the distance of $2.90 \mathrm{~m}$ from volunteer in order to capture the image hip to foot when he was bearing.

After the collection of the second image, the volunteer was placed in the supine position, anatomical points rescheduled and instructed to maintain position without rotation of the lower limbs, ie, keeping the hip in a neutral position (lying with feet parallel - DPP), knees extended, relaxed ankle, thus keeping your feet parallel and quadriceps muscles relaxed (Figure 1C). For the acquisition of the fourth image was changed just the positioning of the feet (lying with feet abducted - DPA), which are adjusted in the same way that the second image ortostatismo 9 (Figure 1D). For this position was made a positioner that kept the legs of volunteers with external rotation desired. At this stage of acquiring images with the volunteer supine, the camera was positioned in a lateral support to the mat, parallel to the ground and at a height of $1.70 \mathrm{~m}$ in order to capture the image of the hip to the foot of each volunteer.

The alignment of the lower limb of the volunteers was controlled by positioning / rotation of membership, without other adjustments related to the joints of the foot or hip ${ }^{5}$.

The entire process of marking the anatomical landmarks and image acquisition was performed three times in each of four positions in said sequence, totaling 12 markings / images per volunteer so that three values was obtained for each angular position being used to statistical analysis the average of three values obtained at each position. The importance of the points between each redial picture taking in the positions analyzed was important because of the possible change of location paths adhesive when it rolled members and / or modified up posture of 9 volunteers.

Finalized the registration of these images were transported to a computer, where we proceeded to analysis using computerized biophotogrammetry through the application ALCimage $2.1 \circledR$. Angular measurements were verified from the union of anatomical points previously marked. To calculate the $\mathrm{Q}$ angle was drawn a line that came from the anterior superior iliac spine to the center of the patella and thence to the tibial tuberosity by drawing an angle corresponding to the quadriceps angle. 
In order to check the difference between the values of the angle $\mathrm{Q}$ between members postures evaluated, was used the Student $\mathrm{t}$ test, and the comparison between the values with and without rotation of the lower limb. To check for possible differences in $\mathrm{Q}$ angle cross-comparison of the four positions of each limb, was used analysis of variance (ANOVA) followed by Tukey test. The level of significance was set at $p$ less than $5 \%$.

\section{Results}

The average age of male subjects was $21.33 \pm 2.20$, and female literacy of $20.81 \pm 3.13$ years.

In Table 1 are shown the descriptive analysis of the data for men and women bilaterally. The four positions analyzed were lying parallel feet (DPP), lying open toe (DPA), orthostatic open toe (OPA) and standing feet parallel (OPP) .

The differences in values between right and left $\mathrm{Q}$ angle were calculated for males and females in all postures and positioning to assess bilateral symmetry, not finding a difference between the angular values in any of four positions evaluated for both sex (Table 2).

Table 3 shows the comparison of the angle $\mathrm{Q}$ between the positions of the feet, separating the lying and standing postures. When analyzed separately for each sex, found a significant difference between the values in upright positions with legs open and feet parallel on the left side in both sexes, the same as for the total group.

Comparing the positions evaluated together without cross between right and left limbs, there was statistical difference only when comparing the standing position and walk parallel orthostatic hemi body left standing open.

\section{Discussion}

Our evaluation of the Q angle of 56 university students of both sexes in order to assess possible variations in measurement. The evaluation was performed following a protocol previously developed based on extensive literature review. The sample was composed of students of both sexes aged 17-31 years. In this age group ${ }^{2,5-7,12,13}$ several studies were conducted, and are present symptoms of anterior knee pain and pathologies such as patellofemoral dysfunction. Also at this age, the knees do not have bone growth, and there are degenerative diseases that could alter the angle $\mathrm{Q}$.

The methodology used in the present study, we used sensitive equipment and reliable, using the caliper and computerized photogrammetry ${ }^{9,11}$. The use of the caliper is suggested by France; Nester ${ }^{9}$, as an indispensable tool for the demarcation of anatomical landmarks difficult location, minimizing errors in this item. Another important item was the demarcation and getting pictures taken at ${ }^{3}$, allowing a more reliable the results ${ }^{9}$. Finally, the methodology used to select a reliable and validated tool, computerized biophotogrammetry, which allows accurate quantitation and non- invasive ${ }^{11}$. Studies such as Tsujimoto et al. ${ }^{13}$ used the
CT or radiography, which are reliable resources, but costly, and expose the volunteer radiation. Other tests such as Tomsich et al. ${ }^{17}$, Kuhn et al. ${ }^{4}$, was used a goniometer, which has questionable reliability and reproducibility.

Assessment of quadriceps angle is commonly performed unilaterally, since the members would be symmetrical. However, Livingston ${ }^{18}$ emphasizes the need for studies with bilateral assessment of members. This study compared the $Q$ value of the angle bilaterally resulting in a symmetry in all positions statistical analysis. Just as Herrington; Nester ${ }^{7}$, assessing 109 volunteers in the standing position, feet parallel. This confirms the reliability of the current data, as the author mentioned herein evaluated a larger group finding similar results to this study. Already Hahn; Foldspang $^{11}$ in 339 athletes found differences between the right and left Q angles. Livingston; Spaulding ${ }^{5}$, the reason for this difference is not yet clear, suggesting there is no explanation for this. Livingston; Mandingo ${ }^{8}$, the difference in values between both sides, is explained by the higher tropism and muscle tone on the dominant side, which would cause a force on the patella displaces it and decreasing the value of the angle. The discrepancy between the results of the present study and Hahn; Foldspang ${ }^{11}$, due to use of more accurate methods, is to use the average of three measurements, and the use of the caliper to locate the center of the patella.

The literature suggested the use of supine and standing postures $5,6,8,11,18$, linking these to external and internal rotation of the lower limbs ${ }^{5,7,19}$. Another variable in the evaluation of the $\mathrm{Q}$ angle is contraction or relaxation of the quadriceps muscle ${ }^{5,6,8,15-17,20}$ because the patella rises when this muscle is triggered $15,17,18,20$. That said, this study evaluated the $\mathrm{Q}$ angle with the quadriceps muscle relaxed ever, as well as being most used method in current studies $5,6,8,15,13,18,20$ wanted to evaluate the said angle without changes imposed by the contraction muscle .

The current study evaluated 56 volunteers, asymptomatic and showed no difference between the values by changing the angular rotations of the lower limbs in the supine position. Olerud; Berg $^{19}$, assessed 34 asymptomatic individuals with internal and external rotations in the supine position, found that the amplitude of the $\mathrm{Q}$ angle increases in internal rotation and external rotation decreases. This difference in results is attributed to the greater number of volunteers in the current study, by using up method for localization of anatomical points more reliable, and use is the average of three values for each position, which provides greater reliability and veracity of the results presented. Comparing the values of the angle in the standing position with the leg rotated internally and externally, in both sexes, revealed no difference only on the left side. Livingston; Spaulding ${ }^{5}$, rated the Q angle in the standing position in 20 individuals of both sexes, through computerized analysis in three positions. They found differences in the comparison between all positions for both members. This study found similar results, since significant difference was found between the rotations in standing 
position, for both sexes, the left lower limb. When referring to the right side, dominant in $95 \%$ of the population, this difference was not found. Attributed to it once more to the fact that we use is the method most thorough evaluation of this angle. As suggested by France \& Nester ${ }^{9}$, to obtain results more confident and reduce evaluation errors, material is used for precise location of the center of the patella, and takes place three measurements of the angle. In addition, this study evaluated a larger number of volunteers, giving greater credibility to our results when compared to the study of Livingston; Spaulding 5 .

The right lower limb was not found difference between the placement of members with internal and external rotation bearing. Among the possible explanations is the possibility that there changes in muscle electrical activity between members of dominant and non-dominant, such a statement is quoted by Ounpuu; Winter ${ }^{21}$, Bagesteiro; Sainburg ${ }^{22}$, show no difference in central motor control, keeping the muscles of the lower limbs more dominant tone. Changes in the electrical activity of muscle and torque can be present even in subjects evaluated with the request for relaxation of the muscles of the lower limb, because changes in the alignment, as tibial rotation and femoral neck antiversion generate co-contractions in the muscles of the knee and hip regardless of the wishes of the volunteer as reported by Bagesteiro; Sainburg ${ }^{22}$. This in turn could alter the positioning member, causing alteration of the angle Q. Another possible explanation for the difference has occurred between the dominant and non-dominant rotation is in the femur, as described by and Sanfridsson et al. ${ }^{23}$, to report that the biomechanics of the lower limbs varies according to the position of the member may medial rotation of the femur lead to an increase of the values of the angle $\mathrm{Q}$, and both, or be associated tibial rotation. However, these variables were not controlled in this study.

Livingston; Spaulding 5 , after studying the $\mathrm{Q}$ angle in the standing position with different rotations, concluded that the ideal position is standing with feet parallel. The assessment with external rotation is not recommended because it produces discomfort to the patient and may represent an angle changed. This study agrees with the above- mentioned regarding the discomfort of maintaining external rotation once the volunteers reported more discomfort and greater difficulty maintaining quadriceps relaxed in this position. Thus Livingston; Spaulding 5 suggest that in future studies, whether used upright posture and feet parallel. Moreover, Olerud; Berg ${ }^{19}$, report that the evaluation should be in a supine posture, and this is the best reported to evaluate the angle Q. Observing the variables, there is the conviction that an important point when evaluating the angle $\mathrm{Q}$, is used for precise methodology, reducing measurement errors. How to correct posture, highlight the supine position, for not influence muscle and femoral rotations imposed by orthostatic ${ }^{16}$. With respect to rotation, the inner seems to be the best, being easily positioned as they do not require the positioned can be performed at any location.
This study is limited with regard to the control of the positioning of the femoral neck (femoral neck antiversion), since no radiographs were analyzed to measure this variable.

\section{Conclusion}

From the results obtained, it is concluded that there there is little or no difference between the analyzed positions, ie, the angle $Q$ values do not change with the rotation member. Thus, it can be concluded that in the supine position there is asymmetry independent of the rotation angle $\mathrm{Q}$ of the hip, which does not occur in the standing position. From the conclusion above, it can be suggested that the $\mathrm{Q}$ angle can be measured in the supine position without rotation of membership, this position, easily adopted and standardized for measuring this angle clinically.

\section{Thanks}

Thanks to CAPES-PROSUP for the scholarship Master.

\section{References}

[1] Heiderscheit BC, Hamill J, Van Emmerik REA. Q-angle influences on the variability of lower extremity coordination during running. Med Sci Sports Exerc. 1999; 31(9):13131319.

[2] Heiderscheit BC, Hamill J, Caldwell GE. Influence of Qangle on lower-extremity running kinematics. JOSPT 2000; 30(5):271-278.

[3] Biedert RM \& Warnke, K. Correlation between the Q angle and the patella position: a clinical and axial computed tomography evaluation. Arch Orthop Trauma Surg 2001; 121:346-349.

[4] Kuhn R, Yochum TR, Cherry AR, Rodgers SS. Immediate changes in the Quadriceps Femoris angle after insertion of an orthotic device. J Maniopulative Physio Ther 2002; 25(7):465-470.

[5] Livingston LA \& Spaulding SJ. Measurement of the Quadriceps Angle Using Standardized Foot Positions. J Athl Train 2002; 37(3):252-255.

[6] Herrington L \& Nester C. Q-angle undervalued? The relationship between Q-angle and medio-lateral position of the patella. Clin Biomech 2004; 19(10):1070-1073.

[7] Melo de Paula GM, Molinero de Paula VR, Almeida GJM, Machado VEI, Baraúna MA, Bevilaqua-Grosso D. Correlação entre a dor anterior do joelho e a medida do ângulo Q por intermédio da fotogrametria computadorizada. Rev Bras Fis 2004; 8(1):39-43.

[8] Livingston LA \& Mandingo JL. Bilateral Q angle asymmetry and anterior knee pain syndrome. Clin Biomech $1999 ; 14(1): 7-13$.

[9] France, L \& Nester, C. Effect of errors in the identification of anatomical landmarks on the accuracy of Q angle values. Clin Biomech 2001; 16(8):710-713. 
[10] Devan MR, Pescatello LS, Faghri JA. A Prospective Study of Overuse Knee Injuries Among Female Athletes With Muscle Imbalances and Structural Abnormalities. J Athl Train 2004; 39(3):263-267.

[11] Hahn T \& Foldspang A. The Q angle and sport. Scand J Med Sci Sports. 1997; 7(1):43-8.

[12] Lathinghouse LH \& Trimble MH. Effects of isometric quadriceps activation on the Q-angle in women before and after quadriceps exercise. JOSPT 2000; 30(4):211-6.

[13] Tsujimoto K, Kurosaka M, Yoshiya S, Mizuno K. Radiographic and computed tomographic analysis of the po sition of the tibial tubercle in recurrent dislocation and subluxation of the patella. Am J Knee Surg 2000; 13(2):838.

[14] Iunes DH, Castro FA, Salgado HS, Moura IC, Oliveira AS, Bevilaqua-Grossi D. Confiabilidade Intra e Interexaminadores e Repetibilidade da Avaliação Postural pela Fotogrametria. Rev Bras Fis 2005; 9(3):327-334.

[15] Livingston LA. The quadriceps angle: a review of the literature. JOSPT 1998; 28(2):105-9.

[16] Woodland LH \& Francis RS. Parameters and comparisons of the quadriceps angle of college-aged men and women in the supine and standing positions. Am J Sports Med 1992;
20(2):208-11

[17] Tomsich DA, Nitz AJ, Threlkeld AJ, Shapiro R. Patellofemoral alignment: reliability. JOSPT 1996; 23(3):200-8.

[18] Huberti HH \& Hayes WC. Patellofemoral contact pressures: the influence of q-angle and tendofemoral contact. J Bone Joint Surg Am. 1984; 66(5):715-24.

[19] Olerud C \& Berg P. The variation of the Q angle with different positions of the foot. Clin Orthop. 1984; 191:162-5.

[20] Raveendranath R, Nachiket S, Sujatha N, Priya R, Rema D. Bilateral Variability of the Quadriceps Angle (Q angle) in an Adult Indian Population. Iran J Basic Med Sci. 2011 Sep;14(5):465-71.

[21] Ounpuu S \& Winter DA. Bilateral electromyographical analysis of the lower limbs during walking in normal adults. Electro Clin Neurophysiol. 1989; 72(5):429-38.

[22] Bagesteiro LB \&Sainburg RL Handedness: dominant arm advantages in control of limb dynamics. J Neurophysiol. 2002; 88(5):2408-21.

[23] Sanfridsson J, Arnbjornsson A, Friden T, Ryd L, Svahn G, Jonsson K. Femorotibial rotation and the Q-angle related to the dislocating patella. Acta Radiol. 2001; 42(2):218-24. 